\title{
All right, SQUIRE?
}

\author{
Derek Richards \\ Centre for Evidence-based Dentistry, Oxford.
}

Evidence-based practice (EBP) is about bringing together the best evidence, clinical experience and patients' values in order to make the most appropriate decisions about the care of individual patients. The five steps of EBP are as follows.

1. Asking answerable questions (ASK)

2. Searching for the best evidence (ACQUIRE)

3. Critically appraising the evidence (APPRAISE)

4. Applying the evidence (APPLY)

5. Evaluating the outcome (ASSESS)

These were first described in $1992^{1}$ and considered in the Sicily statement on Evidencebased Practice ${ }^{2}$ to be key competencies.

The increased focus that EBP has brought to the appraisal of the healthcare literature, one of these key competencies, has highlighted issues with both the use of appropriate research designs and the quality of reporting of the findings. Unfortunately, all too often good research is undermined by poor quality reporting. This has led to the development of recommendations for the reporting of different types of study. The first of these was the CONSORT statement in $2001 .^{3}$ Since then, reporting guidelines have been developed for a range of study designs (see Table 1) and an umbrella organisation has emerged, the EQUATOR Network, which we described in Evidence-based Dentistry last year. ${ }^{4}$ The network aims to enhance the quality and transparency of health research and its website (www.equator-network.org) has links to other internet resources and references for a wide range of reporting guidelines. Some key examples of the latter are highlighted in Table 1.

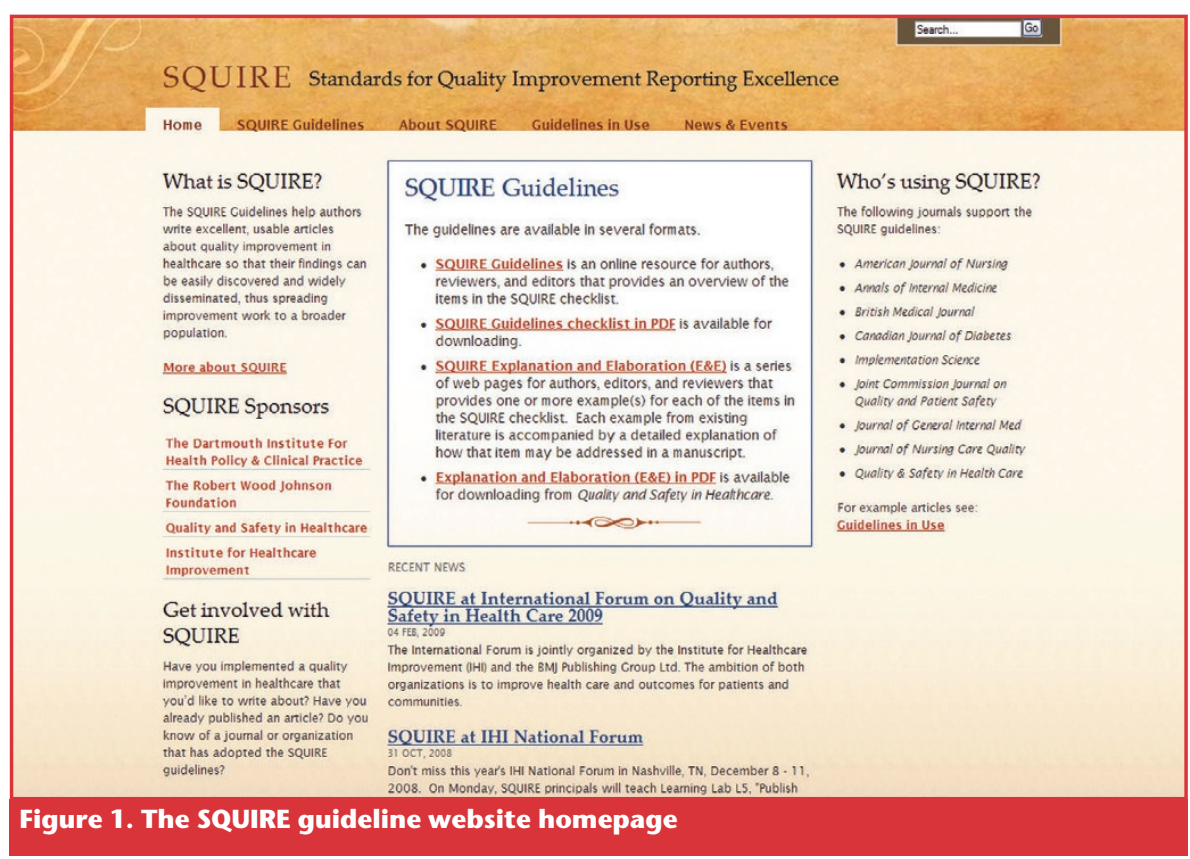

Table 1. Key reporting guidelines for different study designs

\begin{tabular}{|c|c|c|}
\hline Study type & Guideline & URL \\
\hline Experimental studies & CONSORT statement ${ }^{3}$ (Consolidated Standards of Reporting Trials) & www.consort-statement.org \\
\hline Diagnostic accuracy studies & $\begin{array}{l}\text { STARD statement }{ }^{5} \text { (Standards for the Reporting of Diagnostic } \\
\text { accuracy studies) }\end{array}$ & www.stard-statement.org/ \\
\hline $\begin{array}{l}\text { Observational studies } \\
\text { in epidemiology }\end{array}$ & $\begin{array}{l}\text { STROBE statement }{ }^{6} \text { (Strengthening the Reporting of Observational } \\
\text { studies in Epidemiology) }\end{array}$ & www.strobe-statement.org \\
\hline $\begin{array}{l}\text { Systematic reviews and } \\
\text { meta-analyses }\end{array}$ & $\begin{array}{l}\text { QUOROM, }{ }^{7} \text { recently renamed PRISMA }{ }^{8} \text { (Quality of Reporting of } \\
\text { Meta-analyses; Preferred Reporting Items for Systematic Reviews } \\
\text { and Meta-Analyses) }\end{array}$ & $\begin{array}{l}\text { www.consort-statement.org/mod_product/ } \\
\text { uploads/QUOROM\%20Statement\%201999.pdf }\end{array}$ \\
\hline $\begin{array}{l}\text { Meta-analyses of } \\
\text { observational studies }\end{array}$ & MOOSE$^{9}$ (Meta-analysis Of Observational Studies in Epidemiology) & $\begin{array}{l}\text { www.consort-statement.org/mod_product/ } \\
\text { uploads/MOOSE\%20Statement\%202000.pdf }\end{array}$ \\
\hline Qualitative research & COREQ $^{10}$ (Consolidated criteria for Reporting Qualitative research) & None \\
\hline
\end{tabular}


These reporting guidelines are not only useful for getting your study published when it is completed but can also be helpful during the initial development stage.

The SQUIRE guidelines, ${ }^{11}$ which are directed towards improving the standard of reporting of studies that investigate how to improve quality and safety of care. These current guidelines are a refinement of draft guidelines first proposed in $2005^{12}$ and are available from the SQUIRE website (www.squire-statement.org/index.php). The guideline is available on the internet in several formats, including the 19-point checklist and an online resource that provides a detailed overview of the items in the checklist.

Quality improvement is more of an applied science than an academic discipline and consequently the guideline developers have tried to maintain a balance between experimental and pragmatic methods. With significant efforts and funding being applied to improving quality in healthcare, it is important also to raise standards in and dissemination of published work. A recent review $^{13}$ has shown that the CONSORT statement, the first of these recent reporting guidelines, has resulted in improved reporting of randomised controlled trials. Hopefully the SQUIRE guidelines will have a similar effect.

1. Cook DJ, Jaeschke R, Guyatt GH. Critical appraisal of therapeutic interventions in the intensive care unit: human monoclonal antibody treatment in sepsis. Journal club of the Hamilton Regional Critical Care Group. J Intensive Care Med 1992; 7: 275-282.

2. Dawes M, Summerskill W, Glasziou P, et al. Sicily statement on evidence-based practice. BMC Med Educ 2005; 5: 1 .

3. Richards D. The EQUATOR network and website. Evid Based Dent 2007; 8: 117.

4. Moher D, Schulz KF, Altman DG. The CONSORT statement: revised recommendations for improving the quality of reports of parallel-group randomised trials. Lancet 2001; 357: 1191-1194.

5. Bossuyt PM, Reitsma JB, Bruns DE, et al. Towards complete and accurate reporting of studies of diagnostic accuracy: the STARD initiative. Br Med I 2003; 326: 41-44.

6. Vandenbroucke JP, von Elm E, Altman DG, et al. Strengthening the reporting of observational studies in epidemiology (STROBE): explanation and elaboration. PLoS Med 2007; 4: e297.

7. Moher D, Cook DJ, Eastwood S, Olkin I, Rennie D, Stroup DF. Improving the quality of reports of meta-analyses of randomised controlled trials: the QUOROM statement. Quality of reporting of metaanalyses. Lancet 1999; 354: 1896-1900.

8. PLoS Medicine Editors. Many reviews are systematic but some are more transparent and completely reported than others. PLoS Med 2007; 4: e147.

9. Stroup DF, Berlin JA, Morton SC, et al. Meta-analysis of observational studies in epidemiology: a proposal for reporting. Meta-analysis of observational studies in epidemiology (MOOSE) group. J Am Med Assoc 2000; 283: 2008-2012.

10. Tong A, Sainsbury P, Craig J. Consolidated criteria for reporting qualitative research (COREQ): a 32-item checklist for interviews and focus groups. Int I Qual Health Care 2007; 19: 349-357.

11. Davidoff F, Batalden P, Stevens D, Ogrinc G, Mooney SE. Publication guidelines for quality improvement studies in health care: evolution of the SQUIRE project. Br Med J 2009; 338: 402-404.

12. Davidoff F, Batalden P. Toward stronger evidence on quality improvement. Draft publication guidelines: the beginning of a consensus project. Qual Saf Health Care 2005; 14: 319-325.

13. Plint AC, Moher D, Morrison A, et al. Does the CONSORT checklist improve the quality of reports of randomised controlled trials? A systematic review. Med J Aust 2006; 185: 263-267.

Evidence-Based Dentistry (2009) 10, 57-58 doi:10.1038/sj.ebd.640657 